\title{
$\mathrm{SClE}$

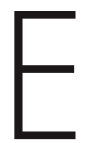

Received: 9 October 2017 Accepted: 19 February 2018

Published: 10 April 2018

\section{library, a quantum-chemical database of molecular properties for force field development}

\section{Mohammad M. Ghahremanpour ${ }^{1}$, Paul J. van Maaren ${ }^{1}$ \& David van der Spoel ${ }^{1}$}

Data quality as well as library size are crucial issues for force field development. In order to predict molecular properties in a large chemical space, the foundation to build force fields on needs to encompass a large variety of chemical compounds. The tabulated molecular physicochemical properties also need to be accurate. Due to the limited transparency in data used for development of existing force fields it is hard to establish data quality and reusability is low. This paper presents the Alexandria library as an open and freely accessible database of optimized molecular geometries, frequencies, electrostatic moments up to the hexadecupole, electrostatic potential, polarizabilities, and thermochemistry, obtained from quantum chemistry calculations for 2704 compounds. Values are tabulated and where available compared to experimental data. This library can assist systematic development and training of empirical force fields for a broad range of molecules.

\begin{tabular}{|l|l|}
\hline $\begin{array}{l}\text { Design Type(s) } \\
\text { Measurement Type(s) }\end{array}$ & data integration objective molecular physical property analysis objective \\
\hline Technology Type(s) & Computational Chemistry \\
\hline Factor Type(s) & \\
\hline Sample Characteristic(s) &
\end{tabular}

${ }^{1}$ Uppsala Centre for Computational Chemistry, Science for Life Laboratory, Department of Cell and Molecular Biology, Uppsala University, Husargatan 3, Box 596, SE-75124 Uppsala, Sweden. Correspondence and requests for materials should be addressed to D.v.d.S. (email: david.vanderspoel@icm.uu.se). 


\section{Background \& Summary}

Chemical space is spanned by all possible molecules that are energetically stable ${ }^{1}$. The to date largest generated database (GDB-17) contains 166.4 billion molecules of up to 17 atoms of $\mathrm{H}, \mathrm{C}, \mathrm{N}, \mathrm{O}, \mathrm{S}$, and halogens ${ }^{2}$ (a more workable representative subset containing 10 million compounds was published recently as well ${ }^{3}$ ). Computational chemistry has enabled us to virtually explore and exploit the chemical space by predicting physicochemical properties of its compounds ${ }^{4}$. This has helped chemical biologists, for example, to identify bioactive regions of the chemical space ${ }^{4-6}$. The main challenge when dealing with large numbers of compounds is to predict properties with good accuracy at moderate computational cost.

Compounds in the chemical space may vary in size, they may be organic or inorganic, including synthetic- and bio-polymers ${ }^{7,8}$. In addition, the chemistry of life ${ }^{9}$ happens in the liquid phase, which implies that we need to explore the properties of a large range of compounds in at least the gas- and the liquid phases. Hence, the practical tool for navigating chemical space is atomistic molecular simulations based on empirical force fields.

Many areas of materials science and drug discovery have benefited from the application of empirical force fields. High-throughput virtual screening is a promising approach, that has led to the discovery of new materials and drug-like compounds ${ }^{10}$. However, making accurate prediction of properties of molecules from different parts of the chemical space is yet to be achieved since force fields are not readily transferable from one chemical category to another. In other words, the reliability and the applicability of force fields in practice depends on the chemical composition of the compounds under investigation. The main reason is that empirical force fields are in essence derived using supervised machine learning algorithms that can learn from and make predictions on the available data. The quality of the data and the diversity of the molecules in the database determine the domain of accuracy and reliability of the resulting force fields. Therefore, data quality should be carefully considered when developing force fields. However, the databases used for optimizing force fields are rarely published and when they are made available they are in a format that is difficult to use in data-mining. As a result, it is difficult to assess the underlying data quality for the existing force fields.

Several resources are available providing experimental data for physicochemical properties. For instance, the National Institute of Standard and Technology ${ }^{11,12}$ and the Design Institute for Physical Properties ${ }^{13}$ have collected large amounts of experimental molecular properties measured during many decades of research. Due to the size of chemical space there is experimental data only for a small fraction of molecules-most of these databases contain less than ten thousand compounds. In addition, most of the data provided for molecular properties is old and the original sources may not be readily accessible. It would be prohibitively expensive to experimentally determine all the properties of interest for even a small fraction of designed compounds from, e.g., GDB-17. For this reason, the dissemination of quantum chemistry data for a set of assorted molecules is very useful to accelerate progress in empirical force fields. For example, Ramakrishnan et al. ${ }^{14}$ have provided a quantum-chemistry database of molecular geometries and properties for 134,000 molecules at the B3LYP/6-31G(2df,p) level of theory, for development of machine learning tools. Moreover, the ANI-1 database provides off-equilibrium density functional theory (DFT) calculations for 57,454 organic molecules up to 8 heavy atoms including $\mathrm{H}, \mathrm{C}, \mathrm{N}$, and $\mathrm{O}^{15}$. Other databases are available as well at both high ${ }^{16,17}$ and low levels of theory ${ }^{18}$. These resources containing quantum-chemical molecular properties are of interest for optimization of molecular mechanics potentials for small compounds by facilitating the development of machine learning strategies for predicting molecular properties ${ }^{19,20}$.

This paper presents the Alexandria library, an open and freely accessible database of quantumchemically optimized molecular structures and properties of 2704 compounds for empirical force field

\begin{tabular}{|c|c|}
\hline Method & $N_{q m}$ \\
\hline B3LYP/aug-cc-pVTZ & 2500 \\
\hline CBS-QB3 & 2179 \\
\hline G2 & 2096 \\
\hline G3 & 2090 \\
\hline G4 & 2091 \\
\hline HF/6-311G** & 2537 \\
\hline W1BD & 705 \\
\hline W1U & 606 \\
\hline
\end{tabular}

Table 1. The number of calculations for each quantum-chemical method in the library. G2, G3, G4, CBS-QB3, W1BD, and W1U were used to calculate thermochemical properties. The HF/6-311G ${ }^{* *}$ and B3LYP/ aug-cc-pVTZ levels of theories were used to optimize the molecular geometries, determine the electric moments and polarizability, molecular electrostatic potential map, atomic partial charge, vibrational frequencies, and the zero-point vibrational energy. Note that not all calculations have been done for all compounds, therefore some numbers above are lower than the total number of compounds. 


\begin{tabular}{|c|c|}
\hline & Information \\
\hline 1 & IUPAC name \\
\hline 2 & Formula \\
\hline 3 & Total charge \\
\hline 4 & Multplicity \\
\hline 5 & CAS number \\
\hline 6 & ChemSpider ID (CSID) \\
\hline 7 & PubChem ID (CID) \\
\hline 8 & Number of rotatable bonds \\
\hline 9 & StdInChI \\
\hline 10 & InChIKey \\
\hline
\end{tabular}

Table 2. Compound information provided in the repository.

\begin{tabular}{|l|c|c|c|}
\hline Property & N & HF/6-311G** & B3LYP/aug-cc-pVTZ \\
\hline$\alpha\left(\AA^{3}\right)$ & 1198 & $2.39(0.004)$ & $0.43(0.006)$ \\
\hline$\mu(\mathrm{D})$ & 542 & $0.48(0.002)$ & $0.30(0.003)$ \\
\hline
\end{tabular}

Table 3. Root mean square deviation (RMSD) from experiment for polarizability $\alpha$ and dipole moment $\boldsymbol{\mu}$ for compounds where calculations were done at both levels of theory. The RMSD and its error bar are obtained by bootstrapping with 100 iterations. $\mathrm{N}$ is the number of compounds, which is limited by the availability of experimental data.

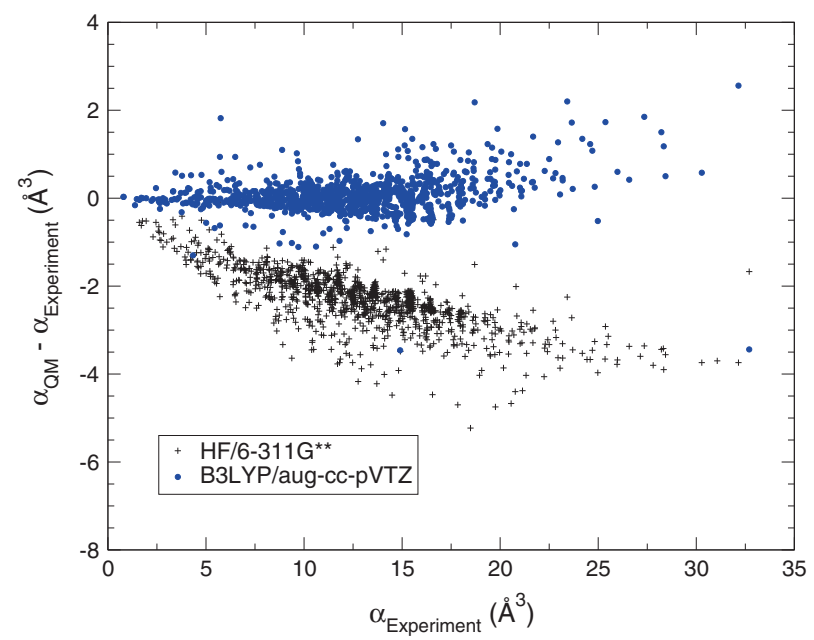

Figure 1. Residual plot for the isotropic polarizability $\alpha$ as calculated at two levels of theory.

development. The name "Alexandria" was adopted to highlight that we aim to collect "all" knowledge in the world, old and new, on molecular properties, just like the legendary library of Alexandria, since it has been established that availability of data rapidly declines with time ${ }^{21}$. The library could also be used for evaluation of density functionals and development of semi-empirical quantum methods. The compounds belong to more than thirty different chemical categories containing functional groups that are common in biomolecules and drug-like compounds. They are predominantly made up of $\mathrm{C}, \mathrm{H}, \mathrm{N}, \mathrm{O}, \mathrm{Si}, \mathrm{P}, \mathrm{S}$, and halogens covering the elements of the GDB-17 chemical space. The library also provides data for some inorganic compounds and metals. The molecular properties provided here are enthalpy of formation, heat capacity, absolute entropy, zero-point vibrational energy, vibrational frequencies, electric moments up to hexadecapole, and polarizability, all in the gas phase. Thermochemistry calculations are in part based on our previous work ${ }^{22}$. In addition, the electrostatic potential on a grid around the compound and the partial atomic charges (Mulliken charges ${ }^{23}$, Hirshfeld charges ${ }^{24}$, ESP charges ${ }^{25}$, and CM5 ${ }^{26}$ ) are computed for each molecule. Where data is available we compare the quantum chemical calculations to experimental data. For transparency, we make the input files used to perform the quantum chemical 


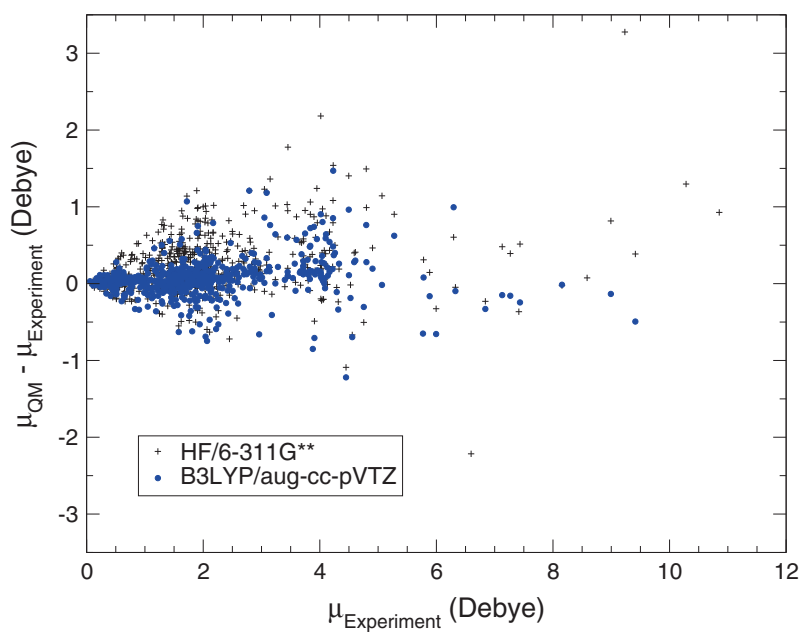

Figure 2. Residual plot for the dipole moment $\mu$ as calculated at two levels of theory.

\begin{tabular}{|c|c|c|c|c|c|}
\hline Formula & $\mathbf{N}_{\exp }$ & $\alpha\left(\AA^{3}\right)$ & $\mathrm{N}_{q m}$ & RMSD $\left(\AA^{3}\right)$ & MSE \\
\hline $\mathrm{C}_{4} \mathrm{H}_{6} \mathrm{O}_{2}$ & 8 & $9(0.3)$ & 6 & 0.1 & 0.1 \\
\hline $\mathrm{C}_{4} \mathrm{H}_{8} \mathrm{O}_{2}$ & 9 & $9(0.2)$ & 9 & 0.2 & 0.0 \\
\hline $\mathrm{C}_{4} \mathrm{H}_{10} \mathrm{O}_{2}$ & 9 & $9(0.1)$ & 8 & 0.1 & 0.0 \\
\hline $\mathrm{C}_{5} \mathrm{H}_{8}$ & 12 & $10(0.5)$ & 10 & 0.2 & 0.2 \\
\hline $\mathrm{C}_{5} \mathrm{H}_{10}$ & 10 & $10(0.3)$ & 9 & 0.2 & -0.2 \\
\hline $\mathrm{C}_{5} \mathrm{H}_{10} \mathrm{O}_{2}$ & 11 & $11(0.1)$ & 11 & 0.1 & -0.1 \\
\hline $\mathrm{C}_{5} \mathrm{H}_{10} \mathrm{O}$ & 10 & $10(0.1)$ & 9 & 0.1 & -0.1 \\
\hline $\mathrm{C}_{5} \mathrm{H}_{12} \mathrm{O}$ & 11 & $11(0.2)$ & 10 & 0.3 & -0.2 \\
\hline $\mathrm{C}_{6} \mathrm{H}_{10}$ & 35 & $12(0.5)$ & 28 & 0.3 & 0.1 \\
\hline $\mathrm{C}_{6} \mathrm{H}_{12} \mathrm{O}_{2}$ & 10 & $13(0.0)$ & 8 & 0.1 & -0.0 \\
\hline $\mathrm{C}_{6} \mathrm{H}_{12}$ & 30 & $12(0.3)$ & 29 & 0.2 & -0.2 \\
\hline $\mathrm{C}_{6} \mathrm{H}_{12} \mathrm{O}$ & 11 & $12(0.3)$ & 9 & 0.2 & -0.1 \\
\hline $\mathrm{C}_{6} \mathrm{H}_{14} \mathrm{O}$ & 14 & $12(0.1)$ & 13 & 0.2 & -0.1 \\
\hline $\mathrm{C}_{7} \mathrm{H}_{9} \mathrm{~N}$ & 12 & $14(0.3)$ & 7 & 0.1 & 0.1 \\
\hline $\mathrm{C}_{7} \mathrm{H}_{12}$ & 23 & $13(0.2)$ & 21 & 0.2 & -0.1 \\
\hline $\mathrm{C}_{7} \mathrm{H}_{14}$ & 44 & $13(0.3)$ & 41 & 0.2 & -0.2 \\
\hline $\mathrm{C}_{7} \mathrm{H}_{14} \mathrm{O}$ & 17 & $14(0.2)$ & 8 & 0.2 & -0.2 \\
\hline $\mathrm{C}_{7} \mathrm{H}_{16}$ & 9 & $14(0.1)$ & 9 & 0.3 & -0.3 \\
\hline $\mathrm{C}_{8} \mathrm{H}_{10} \mathrm{O}$ & 9 & $15(0.1)$ & 5 & 0.2 & 0.1 \\
\hline $\mathrm{C}_{8} \mathrm{H}_{11} \mathrm{~N}$ & 9 & $16(0.4)$ & 5 & 0.4 & 0.2 \\
\hline $\mathrm{C}_{8} \mathrm{H}_{16}$ & 113 & $15(0.3)$ & 109 & 0.3 & -0.2 \\
\hline $\mathrm{C}_{8} \mathrm{H}_{18}$ & 18 & $15(0.1)$ & 16 & 0.4 & -0.4 \\
\hline $\mathrm{C}_{9} \mathrm{H}_{10}$ & 8 & $16(0.4)$ & 6 & 0.7 & 0.6 \\
\hline $\mathrm{C}_{9} \mathrm{H}_{12}$ & 8 & $16(0.1)$ & 7 & 0.1 & 0.1 \\
\hline $\mathrm{C}_{9} \mathrm{H}_{18}$ & 31 & $17(0.2)$ & 25 & 0.4 & -0.4 \\
\hline $\mathrm{C}_{9} \mathrm{H}_{18} \mathrm{O}$ & 9 & $17(0.1)$ & 2 & 0.5 & -0.5 \\
\hline $\mathrm{C}_{9} \mathrm{H}_{20}$ & 16 & $17(0.1)$ & 6 & 0.2 & -0.2 \\
\hline $\mathrm{C}_{10} \mathrm{H}_{14}$ & 19 & $18(0.1)$ & 12 & 0.2 & 0.1 \\
\hline $\mathrm{C}_{10} \mathrm{H}_{22}$ & 14 & $19(0.1)$ & 3 & 0.1 & -0.0 \\
\hline
\end{tabular}

Table 4. Chemical space analysis of polarizability $\boldsymbol{\alpha}$. Number of compounds with experimental data $\mathrm{N}_{\text {exp }}$, experimental average $\alpha$ for all isomers with standard deviation within brackets, number of compounds with B3LYP/aug-cc-pVTZ calculations $\mathrm{N}_{q m}$, root mean square deviation (RMSD) between calculation and experiment, mean signed error (MSE) in calculations. 


\begin{tabular}{|c|c|c|c|c|c|}
\hline Formula & $\mathrm{N}_{\exp }$ & $\mathrm{s}^{0}(\mathrm{~J} / \mathrm{mol} \mathrm{K})$ & $\mathrm{N}_{q m}$ & RMSD (J/mol K) & MSE \\
\hline $\mathrm{C}_{4} \mathrm{H}_{8} \mathrm{O}_{2}$ & 12 & $349(29.0)$ & 12 & 15.9 & 8.1 \\
\hline $\mathrm{C}_{4} \mathrm{H}_{10} \mathrm{O}_{2}$ & 8 & $384(11.8)$ & 7 & 16.5 & -8.9 \\
\hline $\mathrm{C}_{5} \mathrm{H}_{8}$ & 11 & $318(16.0)$ & 10 & 4.8 & 1.1 \\
\hline $\mathrm{C}_{5} \mathrm{H}_{10}$ & 10 & $327(18.1)$ & 10 & 8.1 & 0.1 \\
\hline $\mathrm{C}_{5} \mathrm{H}_{10} \mathrm{O}_{2}$ & 11 & $394(11.7)$ & 9 & 10.4 & 4.1 \\
\hline $\mathrm{C}_{5} \mathrm{H}_{12} \mathrm{O}$ & 12 & $381(11.5)$ & 11 & 7.0 & -3.4 \\
\hline $\mathrm{C}_{6} \mathrm{H}_{10}$ & 20 & $354(17.7)$ & 17 & 8.1 & 0.6 \\
\hline $\mathrm{C}_{6} \mathrm{H}_{12} \mathrm{O}_{2}$ & 10 & $444(21.2)$ & 10 & 18.6 & -1.8 \\
\hline $\mathrm{C}_{6} \mathrm{H}_{12}$ & 19 & $368(20.6)$ & 19 & 5.8 & -0.9 \\
\hline $\mathrm{C}_{6} \mathrm{H}_{12} \mathrm{O}$ & 8 & $402(30.2)$ & 5 & 8.8 & -0.9 \\
\hline $\mathrm{C}_{6} \mathrm{H}_{14} \mathrm{O}_{2}$ & 8 & $461(22.2)$ & 4 & 17.1 & -9.7 \\
\hline $\mathrm{C}_{6} \mathrm{H}_{14} \mathrm{O}$ & 14 & $424(12.2)$ & 9 & 8.1 & -2.6 \\
\hline $\mathrm{C}_{7} \mathrm{H}_{9} \mathrm{~N}$ & 9 & $355(6.8)$ & 7 & 10.2 & 3.4 \\
\hline $\mathrm{C}_{7} \mathrm{H}_{12}$ & 23 & $375(26.3)$ & 23 & 9.5 & -2.5 \\
\hline $\mathrm{C}_{7} \mathrm{H}_{14}$ & 20 & $395(29.9)$ & 19 & 8.1 & -2.7 \\
\hline $\mathrm{C}_{7} \mathrm{H}_{14} \mathrm{O}$ & 15 & $417(33.4)$ & 6 & 17.0 & -0.1 \\
\hline $\mathrm{C}_{7} \mathrm{H}_{16}$ & 9 & $408(14.9)$ & 9 & 9.4 & 5.3 \\
\hline $\mathrm{C}_{8} \mathrm{H}_{10} \mathrm{O}$ & 12 & $395(5.2)$ & 10 & 10.2 & -8.0 \\
\hline $\mathrm{C}_{8} \mathrm{H}_{16}$ & 31 & $414(37.2)$ & 30 & 7.9 & -0.6 \\
\hline $\mathrm{C}_{8} \mathrm{H}_{18}$ & 18 & $441(18.9)$ & 17 & 6.2 & 1.9 \\
\hline $\mathrm{C}_{9} \mathrm{H}_{10}$ & 8 & $382(16.6)$ & 7 & 9.8 & -1.2 \\
\hline $\mathrm{C}_{9} \mathrm{H}_{12}$ & 10 & $392(9.2)$ & 7 & 7.3 & 3.7 \\
\hline $\mathrm{C}_{9} \mathrm{H}_{18}$ & 9 & $463(41.8)$ & 2 & 2.5 & -2.5 \\
\hline $\mathrm{C}_{9} \mathrm{H}_{20}$ & 16 & $470(25.7)$ & 6 & 17.3 & 12.9 \\
\hline $\mathrm{C}_{10} \mathrm{H}_{14}$ & 20 & $428(10.2)$ & 5 & 9.3 & 6.0 \\
\hline $\mathrm{C}_{10} \mathrm{H}_{22}$ & 14 & $522(23.3)$ & 2 & 8.1 & 7.6 \\
\hline
\end{tabular}

Table 5. Chemical space analysis of standard entropy $\mathbf{S}^{\mathbf{0}}$. Number of compounds with experimental data $\mathrm{N}_{\text {exp }}$, experimental average $S^{0}$ for all isomers with standard deviation within brackets, number of compounds with G4 calculations $\mathrm{N}_{q m}$, root mean square deviation (RMSD) between calculation and experiment, mean signed error (MSE) in calculations.

calculations as well as all the output files available. This allows for testing the reproducibility of the quantum chemical data provided in the Alexandria library.

\section{Methods}

Initial structures were downloaded from the PubChem ${ }^{27}$ and the ChemSpider ${ }^{28}$ databases for most of the molecules. The downloaded structures were checked for missing hydrogens and the presence of 3D coordinates. The rest of molecules were generated by Avogadro ${ }^{29}$ or Molden ${ }^{30}$ softwares and their structures were minimized before performing quantum calculations. Quantum chemistry calculations were performed using the Gaussian $09^{31}$ and Gaussian 16 (ref. 32) set of programs. The B3LYP level of density functional theory ${ }^{33-36}$ was used in combination with the aug-cc-pVTZ basis set ${ }^{37-39}$ to optimize molecular geometries and to calculate frequencies, electric moments, polarizabilities, electrostatic potential surface and the corresponding partial atomic charges for each molecule (Table 1). The MerzKollman scheme, as implemented in Gaussian $16^{32}$, was used to generate the grids around the molecule in order to calculate the electrostatic potential surface ${ }^{40,41}$. The B3LYP functional was combined with the aug-cc-pVTZ-PP basis set ${ }^{42}$ to take relativistic pseudopotentials into account for compounds containing iodine. For reference, the same calculations were also performed at the HF/6-311G ${ }^{\star *}$ (refs 43-46) level of theory (Table 1), which is similar to widely used methods to calculate partial atomic charges for virtual screening of large chemical libraries. The G2, G3, G4 (refs 47-51), CBS-QB3 (refs 52,53), W1U, and W1BD (ref. 54) methods were used to calculate enthalpy of formation $\left(\Delta_{f} H^{0}\right)$, heat capacity at constant volume $\left(C_{V}\right)$, and absolute entropy $\left(S^{0}\right)$ at room temperature (Table 1$)$. The Weizmann family of methods was used on a subset of about 600 compounds only, due to computational cost. The procedure of thermochemistry calculations has been explained in detail in our previous work ${ }^{22}$.

The OpenBabel program (version 2.4.1) ${ }^{55}$ was used to determine the number of rotatable bonds based on the optimized geometry for each molecule. The results, wherever possible, were compared to the PubChem database ${ }^{27}$ to check for consistency and manually curated in case of discrepancies. We here count bonds as rotatable if they increase the number of unique conformations. In our previous work ${ }^{22}$ we 


\begin{tabular}{|c|c|c|c|c|c|}
\hline Formula & $\mathrm{N}_{\exp }$ & $\mathrm{C}_{\mathrm{v}}(\mathrm{J} / \mathrm{mol} \mathrm{K})$ & $\mathbf{N}_{q m}$ & RMSD (J/mol K) & MSE \\
\hline $\mathrm{C}_{4} \mathrm{H}_{8} \mathrm{O}_{2}$ & 9 & $97(8.7)$ & 9 & 5.2 & 0.8 \\
\hline $\mathrm{C}_{4} \mathrm{H}_{8} \mathrm{O}$ & 8 & $88(7.9)$ & 7 & 4.9 & -3.6 \\
\hline $\mathrm{C}_{5} \mathrm{H}_{8}$ & 12 & $91(7.4)$ & 11 & 3.9 & -2.8 \\
\hline $\mathrm{C}_{5} \mathrm{H}_{10}$ & 10 & $97(8.6)$ & 10 & 5.7 & -2.9 \\
\hline $\mathrm{C}_{5} \mathrm{H}_{10} \mathrm{O}_{2}$ & 11 & $126(2.9)$ & 9 & 9.3 & -6.9 \\
\hline $\mathrm{C}_{5} \mathrm{H}_{12} \mathrm{O}$ & 12 & $127(4.3)$ & 11 & 7.6 & -6.4 \\
\hline $\mathrm{C}_{6} \mathrm{H}_{10}$ & 16 & $110(11.1)$ & 13 & 5.5 & -2.0 \\
\hline $\mathrm{C}_{6} \mathrm{H}_{12} \mathrm{O}_{2}$ & 9 & $148(2.4)$ & 9 & 5.6 & -3.3 \\
\hline $\mathrm{C}_{6} \mathrm{H}_{12}$ & 19 & $121(9.2)$ & 19 & 8.0 & -4.5 \\
\hline $\mathrm{C}_{6} \mathrm{H}_{14} \mathrm{O}$ & 11 & $149(2.0)$ & 7 & 10.0 & -9.0 \\
\hline $\mathrm{C}_{7} \mathrm{H}_{9} \mathrm{~N}$ & 9 & $117(2.7)$ & 7 & 3.6 & -0.4 \\
\hline $\mathrm{C}_{7} \mathrm{H}_{12}$ & 23 & $131(11.4)$ & 23 & 6.5 & -4.4 \\
\hline $\mathrm{C}_{7} \mathrm{H}_{14}$ & 19 & $137(9.8)$ & 18 & 6.2 & -5.2 \\
\hline $\mathrm{C}_{7} \mathrm{H}_{14} \mathrm{O}$ & 14 & 151(10.8) & 6 & 11.6 & -5.5 \\
\hline $\mathrm{C}_{7} \mathrm{H}_{16}$ & 8 & $156(2.7)$ & 8 & 8.6 & -7.6 \\
\hline $\mathrm{C}_{8} \mathrm{H}_{10} \mathrm{O}$ & 12 & $143(8.6)$ & 10 & 8.0 & -5.4 \\
\hline $\mathrm{C}_{8} \mathrm{H}_{16}$ & 18 & $156(10.7)$ & 18 & 8.0 & -7.1 \\
\hline $\mathrm{C}_{8} \mathrm{H}_{18}$ & 18 & $179(2.8)$ & 17 & 10.4 & -9.7 \\
\hline $\mathrm{C}_{9} \mathrm{H}_{10}$ & 8 & $133(4.8)$ & 7 & 3.2 & -2.2 \\
\hline $\mathrm{C}_{9} \mathrm{H}_{12}$ & 10 & $143(4.3)$ & 7 & 3.8 & -1.3 \\
\hline $\mathrm{C}_{9} \mathrm{H}_{20}$ & 16 & $201(3.4)$ & 6 & 14.7 & -14.6 \\
\hline $\mathrm{C}_{10} \mathrm{H}_{14}$ & 20 & $170(3.8)$ & 5 & 5.3 & -4.4 \\
\hline $\mathrm{C}_{10} \mathrm{H}_{22}$ & 14 & $223(2.5)$ & 2 & 17.6 & -17.5 \\
\hline
\end{tabular}

Table 6. Chemical space analysis of heat capacity at constant volume $\mathbf{C}_{\mathbf{v}}$. Number of compounds with experimental data $\mathrm{N}_{\text {exp }}$, experimental average $\mathrm{C}_{\mathrm{v}}$ for all isomers with standard deviation within brackets, number of compounds with G4 calculations $\mathrm{N}_{q m}$, root mean square deviation (RMSD) between calculation and experiment, mean signed error (MSE) in calculations.

introduced an OpenBabel tool obthermo to extract thermochemistry data from Gaussian ${ }^{31}$ output files (with the aid of library of atomization energies, provided in OpenBabel (version 2.4.1). This open source tool contributes to our aim to make the data provided here accessible to other workers in the field.

\section{Data Records}

The Alexandria library contains the input (.com) and the output (.log) files in GNU-zip compressed format (.gz) of quantum chemical calculations performed using Gaussian 09 (ref. 31) or Gaussian 16 (ref. 32) (Data Citation 1). All compounds are provided in a single Chemical Markup Language (CML) and in a single Tripos Mol2 (.mol2) file as well. The .mol2 file contains the optimized geometries at the B3LYP/ aug-cc-pVTZ level of theory, the atomic partial charges computed by the ESP fitting algorithm, and the bond information. The molecular electrostatic potential surface used to fit the atomic partial charges is also provided in (compressed) XML files for each compound. This must be used in conjunction with the corresponding coordinates of the compound, that can be extracted from the Gaussian log files using OpenBabel. SMILES fingerprints were also generated for all molecules using the OpenBabel software (version 2.4.1) ${ }^{55}$ and stored in a .smiles file.

For each quantum chemical method, a table is provided in a .csv file (comma-separated value, however since both compound names and InChI identifiers contain comma's, we use the pipe symbol 'I' as a separator). The files include the compound information (Table 2), the calculated and the experimental values of the molecular dipole moment, polarizability and thermochemistry results. These tables can be read using either commercial or open source spreadsheet software but they can also be processed by scripting languages. Further molecular properties are available in the Gaussian log files that can be extracted by OpenBabel software (version 2.4.1) ${ }^{55}$ or other software.

\section{Technical Validation}

\section{Experimental Data}

The experimental results used for the validation of quantum chemistry calculations are taken from several sources ${ }^{13,56-60}$. In some cases the values were cross referenced against the original publication to check for transcription errors. For compounds where multiple values for the same property were found, the average 


\begin{tabular}{|c|c|c|c|c|c|}
\hline Formula & $\mathrm{N}_{\exp }$ & $\Delta_{f} H^{0}(\mathbf{k J} / \mathrm{mol})$ & $\mathbf{N}_{q m}$ & RMSD $(\mathrm{kJ} / \mathrm{mol})$ & MSE \\
\hline $\mathrm{C}_{4} \mathrm{H}_{8} \mathrm{O}_{2}$ & 12 & $-379(63.9)$ & 12 & 14.0 & 9.3 \\
\hline $\mathrm{C}_{4} \mathrm{H}_{8} \mathrm{O}$ & 8 & $-172(42.3)$ & 7 & 3.5 & -0.8 \\
\hline $\mathrm{C}_{4} \mathrm{H}_{10} \mathrm{O}_{2}$ & 10 & $-404(66.4)$ & 9 & 14.6 & 10.9 \\
\hline $\mathrm{C}_{5} \mathrm{H}_{8}$ & 12 & $114(39.3)$ & 11 & 3.2 & 1.7 \\
\hline $\mathrm{C}_{5} \mathrm{H}_{10}$ & 12 & $-23(21.7)$ & 12 & 5.6 & 2.0 \\
\hline $\mathrm{C}_{5} \mathrm{H}_{10} \mathrm{O}_{2}$ & 11 & $-457(36.2)$ & 9 & 10.5 & 2.6 \\
\hline $\mathrm{C}_{5} \mathrm{H}_{10} \mathrm{O}$ & 9 & $-244(13.6)$ & 8 & 8.4 & 3.8 \\
\hline $\mathrm{C}_{5} \mathrm{H}_{12} \mathrm{O}$ & 12 & $-293(21.3)$ & 11 & 7.8 & -0.7 \\
\hline $\mathrm{C}_{6} \mathrm{H}_{10}$ & 20 & $68(41.8)$ & 17 & 7.5 & 2.9 \\
\hline $\mathrm{C}_{6} \mathrm{H}_{12} \mathrm{O}_{2}$ & 11 & $-470(56.7)$ & 11 & 19.1 & 10.5 \\
\hline $\mathrm{C}_{6} \mathrm{H}_{12}$ & 28 & $-52(23.7)$ & 28 & 8.5 & 3.3 \\
\hline $\mathrm{C}_{6} \mathrm{H}_{12} \mathrm{O}$ & 8 & $-267(33.9)$ & 5 & 2.7 & -1.1 \\
\hline $\mathrm{C}_{6} \mathrm{H}_{14} \mathrm{O}_{2}$ & 9 & $-466(34.4)$ & 4 & 17.8 & 11.9 \\
\hline $\mathrm{C}_{6} \mathrm{H}_{14} \mathrm{O}$ & 14 & $-317(19.3)$ & 9 & 6.5 & 0.7 \\
\hline $\mathrm{C}_{7} \mathrm{H}_{9} \mathrm{~N}$ & 9 & $69(15.2)$ & 7 & 7.1 & 1.3 \\
\hline $\mathrm{C}_{7} \mathrm{H}_{12}$ & 28 & $31(54.9)$ & 26 & 8.5 & -0.9 \\
\hline $\mathrm{C}_{7} \mathrm{H}_{14}$ & 44 & $-88(23.0)$ & 43 & 7.2 & 2.6 \\
\hline $\mathrm{C}_{7} \mathrm{H}_{14} \mathrm{O}$ & 15 & $-316(30.4)$ & 6 & 23.7 & 14.6 \\
\hline $\mathrm{C}_{7} \mathrm{H}_{16}$ & 9 & $-197(6.3)$ & 9 & 3.2 & 0.7 \\
\hline $\mathrm{C}_{8} \mathrm{H}_{10} \mathrm{O}$ & 12 & $-148(17.9)$ & 10 & 10.6 & 3.4 \\
\hline $\mathrm{C}_{8} \mathrm{H}_{16}$ & 104 & $-111(25.3)$ & 102 & 6.3 & 1.8 \\
\hline $\mathrm{C}_{8} \mathrm{H}_{18}$ & 18 & $-217(5.0)$ & 17 & 7.7 & 4.9 \\
\hline $\mathrm{C}_{9} \mathrm{H}_{10}$ & 8 & $113(21.0)$ & 7 & 3.0 & -2.3 \\
\hline $\mathrm{C}_{9} \mathrm{H}_{12}$ & 10 & $27(63.1)$ & 7 & 3.4 & -3.3 \\
\hline $\mathrm{C}_{9} \mathrm{H}_{18}$ & 9 & $-146(41.0)$ & 2 & 22.1 & 18.8 \\
\hline $\mathrm{C}_{9} \mathrm{H}_{20}$ & 16 & $-237(6.5)$ & 6 & 25.8 & 19.9 \\
\hline $\mathrm{C}_{10} \mathrm{H}_{14}$ & 20 & $-27(8.2)$ & 5 & 15.0 & 6.1 \\
\hline $\mathrm{C}_{10} \mathrm{H}_{22}$ & 14 & $-260(7.8)$ & 2 & 3.4 & -3.4 \\
\hline
\end{tabular}

Table 7. Chemical space analysis of enthalpy of formation $\boldsymbol{\Delta}_{\boldsymbol{f}} \mathbf{H}^{\mathbf{0}}$. Number of compounds with experimental data $\mathrm{N}_{\text {exp }}$, experimental average $\Delta_{f} \mathrm{H}^{0}$ for all isomers with standard deviation within brackets, number of compounds with G4 calculations $\mathrm{N}_{q m}$, root mean square deviation (RMSD) between calculation and experiment, mean signed error (MSE) in calculations.

and the standard deviation of the values were taken to be the reference value and the uncertainty, respectively ${ }^{22}$. It should be noted that we found approximately 240 suspected errors in the experimental data in our previous work ${ }^{22}$ which are excluded from comparisons in this study. It can obviously not be excluded that there are more errors in the experimental reference data leading to less good agreement with calculations.

\section{Quantum Chemical Calculations}

We have previously benchmarked and validated a number of standard quantum thermochemistry methods used to build the Alexandria library and shown that the G4 theory is a good compromise for thermochemistry calculations in comparison to the other methods ${ }^{22}$. Therefore, we here focus on the validation of optimized geometries, molecular polarizability, and dipole moments.

The optimized geometries were validated by comparing the StdInChI generated from each optimized geometry to the StdInChI obtained from PubChem database ${ }^{27}$. Moreover, the StdInChI obtained from the initial structure is compared to the StdInChI generated from the optimized structure confirming that both the initial and the optimized geometries correspond to the same compound ${ }^{14,61}$. 40 compounds out of 2704 did not pass this test, because StdInChI representations are not unique and thus the generation of StdInChI from Cartesian coordinates is error prone. This problem has been discussed in detail elsewhere ${ }^{14}$. Here, these 40 compounds were validated manually.

DFT calculations of molecular dipole moment and isotropic polarizability were validated by comparing to experiments. The B3LYP/aug-cc-pVTZ level of theory ${ }^{34,37-39,62}$ showed much lower RMSD than the HF/6-311G ${ }^{* *}$ level of theory ${ }^{63,64}$ for isotropic polarizability (Table 3). Hartree-Fock calculations with the $6-311 \mathrm{G}^{* *}$ basis set systematically underestimate the molecular isotropic polarizability (Fig. 1). However, the distribution of the residuals is homogenous for the B3LYP calculations with the aug-cc- 
pVTZ basis set (Fig. 1), indicating that B3LYP/aug-cc-pVTZ yields reliable predictions of the isotropic polarizability. The comparison between experimental and quantum-mechanical dipole moments was done for rigid molecules only, because the experimental dipole moment of flexible molecules, which represents an average over the accessible conformations at the experimental temperature, is not comparable to the computed dipole moment of a single conformation at zero Kelvin. Therefore flexible molecules were excluded from the statistics of the calculated dipole moments listed in Table 3 and from the residual plot presented in Fig. 2. In this work, a molecule is considered flexible if it has at least one rotatable bond. The RMSD from experimental dipole moments is found to be $\approx 0.2 \mathrm{D}$ higher for HF/6$311 G^{* *}$ than for B3LYP/aug-cc-pVTZ (Table 3). Fig. 2 also shows that B3LYP with the aug-cc-pVTZ basis set is accurate enough to reproduce experimental dipole moments, and hence, to predict values for molecules where there is no experimental data, at least for those compound categories in this data set.

The experimental and quantum chemical data provided in this paper also allow performing systematic analyses of molecular properties. Such analyses aid in understanding the relation between the chemical composition and the physicochemical properties of molecules. The variation of the experimental isotropic polarizability between different chemical formulae is small (Table 4). The mean signed errors (MSE) show that the B3LYP/aug-cc-pVTZ level of theory slightly underestimates the isotropic polarizability for most of the chemical formulas listed in Table 4. The standard deviation obtained from the experimental thermochemistry data show that the standard entropy (Table 5) and the heat capacity at constant volume (Table 6) can be predicted quite accurately by the chemical formula, while this does not hold for the enthalpy of formation (Table 7). The MSE values show that the G4 theory underestimates the entropy and heat capacity at constant volume (Tables 5 and 6), however, it overestimates the enthalpy of formation for most of the chemical formulas (Table 7).

\section{Usage Notes}

Programs like Molden ${ }^{30}$, Avogadro ${ }^{29}$ and GaussView can be used to visualize and analyze quantum chemical calculations. Moreover, the obthermo ${ }^{22}$ program implemented in the OpenBabel program package (version 2.4.1) ${ }^{55}$ extracts enthalpy of formation, heat capacity at constant volume, and absolute entropy from the Gaussian 09 (ref. 31) and Gaussian 16 (ref. 32) log files. It can also be used to estimate the heat capacity at constant pressure from the calculated heat capacity at constant volume and the temperature derivative of the second virial coefficient, which must then be specified by the user as the input to the program ${ }^{22}$.

\section{References}

1. Kirkpatrick, P. \& Ellis, C. Chemical space. Nature 432, 823 (2004).

2. Reymond, J.-L. The chemical space project. Acc. Chem. Res 48, 722-730 (2015).

3. Visini, R., Awale, M. \& Reymond, J.-L. Fragment database fdb-17. J. Chem. Inf. Model. 57, 700-709 (2017).

4. Lipinski, C. \& Hopkins, A. Navigating chemical space for biology and medicine. Nature 432, 855-861 (2004).

5. Reymond, J.-L. \& Awale, M. Exploring chemical space for drug discovery using the chemical universe database. ACS Chem. Neurosci 3, 649-657 (2012).

6. Orchard, S. et al. Minimum information about a bioactive entity (miabe). Nature Rev. Drug. Discov 10, 661-669 (2011).

7. Dobson, C. M. Chemical space and biology. Nature 432, 824-828 (2004).

8. Lopez-Vallejo, F, Giulianotti, M. A, Houghten, R. A. \& Medina-Franco, J. L. Expanding the medicinally relevant chemical space with compound libraries. Drug. Discov. Today. 17, 718-726 (2012).

9. Marth, J. D. A unified vision of the building blocks of life. Nature Cell Biol. 10, 1015-1016 (2008).

10. Durrant, J. D. \& McCammon, J. A. Molecular dynamics simulations and drug discovery. BMC Biology 9, 71-79 (2011).

11. Chase, M. W. Jr. et al. NIST JANAF thermochemical tables 1985 version 1.0. Tech. Rep. National Institue of Standards http:// kinetics.nist.gov/janaf/ (1985).

12. Chase, M. W. Jr. NIST-JANAF thermochemical tables, fourth edition. J. Phys. Chem. Ref. Data Monograph 9, 1-1951 (1998).

13. Rowley, R. L., Wilding, W. V., Oscarson, J. L., Yang, Y. \& Giles, N. F. Data Compilation of Pure Chemical Properties (Design Institute for Physical Properties (American Institute for Chemical Engineering New York, 2012).

14. Ramakrishnan, R, Dral, P. O., Rupp, M. \& von Lilienfeld, O. A Quantum chemistry structures and properties of 134 kilo molecules. Sci. Data 1, 140022 (2014).

15. Smith, J. S., Isayev, O. \& Roitberg, A. E. ANI-1: A data set of 20M off-equilibrium DFT calculations for organic molecules. Sci Data. 4, 170193 (2017).

16. Simmie, J. M. A database of formation enthalpies of nitrogen species by compound methods (CBS-QB3, CBS-APNO, G3, G4). J. Phys. Chem. A. 119, 10511-10526 (2015).

17. Hait, D. \& Head-Gordon, M. How accurate is density functional theory at predicting dipole moments? an assessment using a new database of 200 benchmark values. Preprint at https://arxiv.org/abs/1709.05075. (2017).

18. Nakata, M. \& Shimazaki, T. PubChemQC project: A large-scale first-principles electronic structure database for data-driven chemistry. J. Chem. Inf. Model. 57, 1300-1308 (2017).

19. Rupp, M., Ramakrishnan, R. \& von Lilienfeld, O. A Machine learning for quantum mechanical properties of atoms in molecules. J. Phys. Chem. Lett. 6, 3309-3313 (2015).

20. Unke, O. T. \& Meuwly, M. Toolkit for the construction of reproducing kernel-based representations of data: Application to multidimensional potential energy surfaces. J. Chem. Inf. Model. 57, 1923-1931 (2017).

21. Vines, T. H. et al. The availability of research data declines rapidly with article age. Curr. Biol. 24, 94-97 (2014).

22. Ghahremanpour, M. M., van Maaren, P. J., Ditz, J., Lindh, R. \& van der Spoel, D. Large-scale calculations of gas phase thermochemistry: Enthalpy of formation, standard entropy and heat capacity. J. Chem. Phys. 145, 114305 (2016).

23. Mulliken, R. S. Electronic population analysis on LCAO-MO molecular wave functions. I. J. Chem. Phys. 23, 1833-1840 (1955).

24. Hirshfeld, F. L. Bonded-atom fragments for describing molecular charge densities. Theor. Chem. Acc. 44, 129-138 (1977).

25. Bayly, C. I., Cieplak, P., Cornell, W. D. \& Kollman, P. A A Well-Behaved Electrostatic Potential Based Method Using Charge Restraints for Deriving Atomic Charges-the RESP Model. J. Phys. Chem 97, 10269-10280 (1993).

26. Marenich, A. V., Jerome, S. V., Cramer, C. J. \& Truhlar, D. G Charge model 5: An extension of Hirshfeld population analysis for the accurate description of molecular interactions in gaseous and condensed phases. J. Chem. Theory Comput. 8, 527-541 (2012). 
27. Kim, S. et al. PubChem Substance and Compound databases. Nucleic Acids Res. 44, 1202-1213 (2016).

28. Pence, H. E. \& Williams, A. Chemspider: An online chemical information resource. J. Chem. Educ. 87, 1123-1124 (2010).

29. Hanwell, M. D. et al. Avogadro: an advanced semantic chemical editor, visualization, and analysis platform. J. Cheminform 4, 17 (2012).

30. Schaftenaar, G. \& Noordik, J. H. Molden: a Pre- and Post-Processing Program for Molecular and Electronic Structures. J. Comput. Aid. Mol. Des 14, 123-134 (2000).

31. Frisch, M. J. et al. Gaussian 09 Revision B 01 (2009) Gaussian Inc.: Wallingford CT.

32. Frisch, M. J. et al. Gaussian 16 Revision A 03 (2016) Gaussian Inc.: Wallingford CT.

33. Hohenberg, P. \& Kohn, W. Inhomogeneous Electron Gas. Phys. Rev 136, B864-B871 (1964).

34. Becke, A. D. Density-functional exchange-energy approximation with correct asymptotic-behavior. Phys. Rev. A 38, 3098-3100 (1988).

35. Lee, C., Yang, W. \& Parr, R. G Development of the Colle-Salvetti correlation-energy formula into a functional of the electron density. Phys. Rev. B 37, 785-789 (1988).

36. Becke, A. D. Density-functional thermochemistry. III. The role of exact exchange. J. Chem. Phys. 98, 5648-5652 (1993).

37. Kendall, R. A., Dunning, T. H. Jr. \& Harrison, R. J. Electron affinities of the first-row atoms revisited. Systematic basis sets and wave functions. J. Chem. Phys. 96, 6796-6806 (1992).

38. Woon, D. E. \& Dunning, T. H. Jr. Benchmark calculations with correlated molecular wave functions. I. Multireference configuration interaction calculations for the second row diatomic hydrides. J. Chem. Phys. 99, 1914-1929 (1993).

39. Woon, D. E. \& Dunning, T. H. Jr. Gaussian basis sets for use in correlated molecular calculations. III. The atoms aluminum through argon. J. Chem. Phys. 98, 1358-1371 (1993).

40. Singh, U. C. \& Kollman, P. A. An Approach to Computing Electrostatic Charges for Molecules. J. Comput. Chem. 5, 129-145 (1984).

41. Besler, B. H., Merz, K. M. Jr. \& Kollman, P. A. Atomic Charges Derived from Semiempirical Methods. J. Comput. Chem 11, 431-439 (1990).

42. Peterson, K. A., Shepler, B. C., Figgen, D. \& Stoll, H. On the spectroscopic and thermochemical properties of clo, bro, io, and their anions. J. Phys. Chem. A 110, 13877-13883 (2006).

43. Hehre, W. J., Ditchfield, R. \& Pople, J. A Self-consistent molecular orbital methods. XII. Further extensions of gaussian-type basis sets for use in molecular orbital studies of organic molecules. J. Chem. Phys. 56, 2257-2261 (1972).

44. Francl, M. M. et al. Selfconsistent molecular orbital methods. XXIII. A polarizationtype basis set for secondrow elements. J. Chem. Phys. 77, 3654-3665 (1982).

45. Clark, T., Chandrasekhar, J., Spitznagel, G. W. \& Schleyer, P. V. R. Efficient diffuse function-augmented basis sets for anion calculations. III. The 3-21+G basis set for first-row elements, Li-F. J. Comput. Chem 4, 294-301 (1983).

46. Gill, P. M., Johnson, B. G., Pople, J. A. \& Frisch, M. J. The performance of the Becke-Lee-Yang-Parr (B-LYP) density functional theory with various basis sets. Chem. Phys. Lett. 197, 499-505 (1992).

47. Pople, J. A., Head-Gordon, M., Fox, D. J., Raghavachari, K. \& Curtiss, L. A. Gaussian-1 theory: A general procedure for prediction of molecular energies. J. Chem. Phys. 90, 5622-5629 (1989).

48. Curtiss, L. A., Jones, C., Trucks, G. W., Raghavachari, K. \& Pople, J. A. Gaussian-1 theory of molecular energies for second-row compounds. J. Chem. Phys. 93, 2537-2545 (1990).

49. Curtiss, L. A., Raghavachari, K., Trucks, G. W. \& Pople, J. A. Gaussian-2 theory for molecular energies of first- and second-row compounds. J. Chem. Phys. 94, 7221-7230 (1991).

50. Curtiss, L. A., Raghavachari, K., Redfern, P. C., Rassolov, V. \& Pople, J. A. Gaussian-3 (G3) theory for molecules containing first and second-row atoms. J. Chem. Phys. 109, 7764-7776 (1998).

51. Curtiss, L. A., Redfern, P. C. \& Raghavachari, K. Gaussian-4 Theory. J. Chem. Phys. 126, 84108 (2007).

52. Montgomery, J. A. Jr., Frisch, M. J., Ochterski, J. W. \& Petersson, G. A. A complete basis set model chemistry. VI. Use of density functional geometries and frequencies. J. Chem. Phys. 110, 2822-2827 (1999).

53. Montgomery, J. A. Jr., Frisch, M. J., Ochterski, J. W. \& Petersson, G. A. A complete basis set model chemistry. VII. Use of the minimum population localization method. J. Chem. Phys. 112, 6532-6542 (2000).

54. Barnes, E. C., Petersson, G. A., Montgomery, J. A., Frisch, M. J. \& Martin, J. M. L. Unrestricted coupled cluster and Brueckner doubles variations of W1 theory. J. Chem. Theory Comput. 5, 2687-2693 (2009).

55. O'Boyle, N. M. et al. Open Babel: An open chemical toolbox. J. Cheminf 3, 33 (2011).

56. Lide, D. R. CRC Handbook of Chemistry and Physics 90th edition (CRC Press Cleveland, Ohio, 2009).

57. Yaws, C. L. Yaws' Handbook of Thermodynamic Properties for Hydrocarbons and Chemicals. Knovel http://www.knovel.com (2009).

58. Yaws, C. L. Yaws' Critical Property Data for Chemical Engineers and Chemists. Knovel http://www.knovel.com (2012).

59. Miller, K. J. Additivity Methods in Molecular Polarizability. J. Am. Chem. Soc. 112, 8542-8553 (1990).

60. Applequist, J., Carl, J. R. \& Fung, K.-K. An Atom Dipole Interaction Model for Molecular Polarizability. Application to Polyatomic Molecules and Determination of Atom Polarizabilities. J. Am. Chem. Soc. 94, 2952-2960 (1972).

61. Lopez, S. A. et al. The harvard organic photovoltaic dataset. Sci. Data 3, 160086 (2016).

62. Dunning, T. H. Jr. \& Peterson, K. A. Approximating the basis set dependence of coupled cluster calculations: Evaluation of perturbation theory approximations for stable molecules. J. Chem. Phys. 1113, 7799-7808 (2000).

63. Roothaan, C. C. J. New Developments in Molecular Orbital Theory. Rev. Mod. Phys. 23, 69-89 (1951).

64. Krishnan, R., Binkley, J. S., Seeger, R. \& Pople, J. A Self-consistent Molecular-orbital Methods. XX. Basis Set for Correlated Wave-functions. J. Chem. Phys. 72, 650-654 (1980).

\section{Data Citations}

1. Ghahremanpour, M. M., van Maaren, P. J. \& van der Spoel, D. Zenodo https://doi.org/10.5281/zenodo.1004711 (2017).

\section{Acknowledgements}

The Swedish research council is acknowledged for financial support to DvdS (grant 2013-5947) and for grants of computer time (SNIC2015-16-33, SNIC2016-34-44) through the High Performance Computing Center North in Umeå, Sweden.

Competing interests: The authors declare no competing interests. 
How to cite this article: Ghahremanpour, M. M. et al. The Alexandria library, a quantum-chemical database of molecular properties for force field development. Sci. Data 5:180062 doi: 10.1038/ sdata.2018.62 (2018).

Publisher's note: Springer Nature remains neutral with regard to jurisdictional claims in published maps and institutional affiliations.

(c) Open Access This article is licensed under a Creative Commons Attribution 4.0 International License, which permits use, sharing, adaptation, distribution and reproduction in any medium or format, as long as you give appropriate credit to the original author(s) and the source, provide a link to the Creative Commons license, and indicate if changes were made. The images or other third party material in this article are included in the article's Creative Commons license, unless indicated otherwise in a credit line to the material. If material is not included in the article's Creative Commons license and your intended use is not permitted by statutory regulation or exceeds the permitted use, you will need to obtain permission directly from the copyright holder. To view a copy of this license, visit http://creativecommons. org/licenses/by/4.0/

The Creative Commons Public Domain Dedication waiver http://creativecommons.org/publicdomain/ zero/1.0/ applies to the metadata files made available in this article.

(C) The Author(s) 2018 